\title{
Calculation of Track Parameters of Alpha Particles with Various Energies and Incident Angles in CR-39 Detector
}

\author{
Ali K. Hussein \\ Department of Physics / College of Education / University of Mosul \\ E-mail: ali_khatab59@yahoo.com
}

(Received 13/10/2013;Accepted 25/11/2013)

\begin{abstract}
In this paper, the bulk etch rate, $V_{B}$ of the CR-39 detector employed, was found experimentally to be equal to $1.49 \mu \mathrm{mh}^{-1}$. Detector samples were irradiated with alpha particles energies from 1 to $5 \mathrm{MeV}$ and incident angles from $20^{\circ}$ to $90^{\circ}$. After etching in a $6.25 \mathrm{~N} \mathrm{NaOH}$ solution kept at $(70 \pm 1)$ ${ }^{\circ} \mathrm{C}$, the lengths of major and minor axes of the alpha track openings were measured, and the track etch rate, $\mathrm{V}_{\mathrm{T}}$ for normal and oblique incidence was calculated. The relationship between $\mathrm{V}_{\mathrm{T}}$ and the track depth, $\mathrm{x}$ of the alpha particle in the detector for normal incidence was studied. Track length, $\mathrm{L}$ and track length growth rate, $\mathrm{dL} / \mathrm{dt}$ were also calculated. These data were used altogether to derive a $\mathrm{V}$ function, which took the functional form of the Brun's function with new constants $\left(\mathrm{a}_{1}=0.091\right.$, $\left.\mathrm{a}_{2}=1.2, \mathrm{a}_{3}=1.6, \mathrm{a}_{4}=1.61, \mathrm{a}_{5}=1.425\right)$. Experimental $\mathrm{V}$ function was compared with those computed by TRACK-VISION program, and a good agreement with three of them was found.
\end{abstract}

Keywords: CR-39, Bulk etch rate $\mathrm{V}_{\mathrm{B}}$, Track etch rate $\mathrm{V}_{\mathrm{T}}$, Major and minor axes, Track length $\mathrm{L}, \mathrm{V}$ function.

\section{مسلبمعامل الثر لجسيمات الفا جلفلت ونوليلسقط مختلفة في الكلثف CR-39}

\section{الملغص}

في هذا البحث، مُ هسب معدل القثط العلم (V) عمليا للكلثف CR-39 المستخدم في هذه الدرلسة إذ وجد النه يساوي

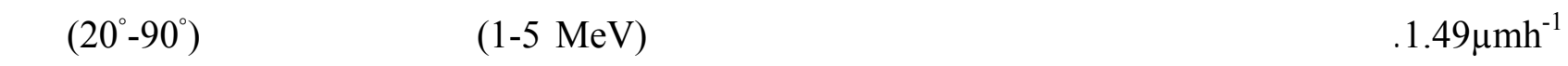
قثطها بمحلول

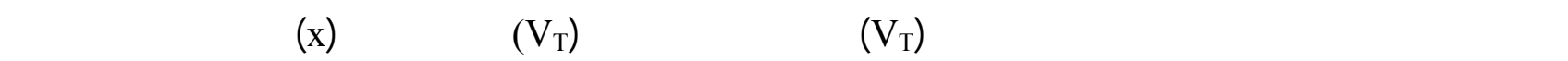

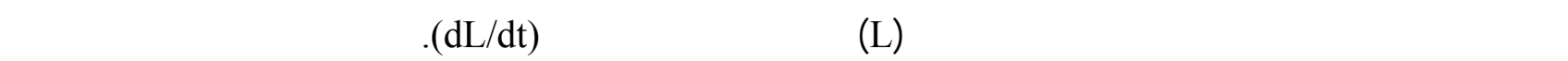

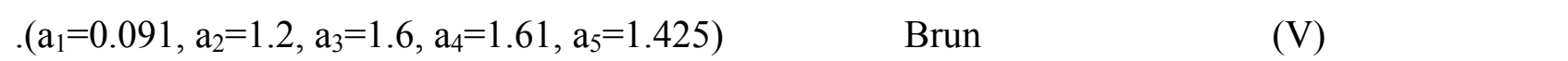

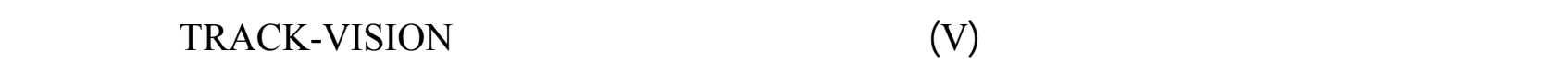
جيدمع ثلاث منها.

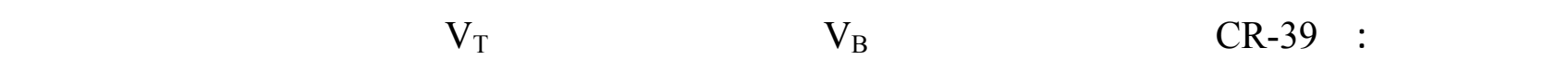
طول الأثر L، الدالة V

\section{INTRODUCTION}

Solid state nuclear track detectors (SSNTDs) are widely used in many fields of science and technology. Nearly almost these applications concern the detection of alpha particles emitted by natural radioactivity; therefore, the response of SSNTDs detectors against alpha particles is of essential interest (Nikezic and $\mathrm{Yu}, 2004$ ). Among their applications are radiation protection, 
environmental radiation monitoring, accelerators, nuclear reactors, neutron monitoring, space research, geology, geophysics and radon studies (Nikezic et al., 2005. Immè et al., 2013). One of the most widely used as SSNTD is made of polyallyldiglycol carbonate, which is commercially available as CR-39 detector in which visible tracks can be formed after ion irradiation and suitable chemical etching condition (Durrani and Bull, 1987). The basic model describing the track geometry considers two different and specific etch velocities: the bulk etch rate, $V_{B}$ (i.e., the rate of chemical etching of the undamaged surface), and the track etch rate, $\mathrm{V}_{\mathrm{T}}$ (i.e., the rate of chemical etching along the ion trajectory). Both etch velocities can be influenced by the chemical structure of the detector material and several additional external conditions such as storage, etching temperature, etchant type, concentration and purity. Moreover, the track etch velocity depends sensitively on particle's type and energy (Hermsdorf, 2012). The sensitivity function V (which is also called the etch rate ratio $\mathrm{V}=\mathrm{V}_{\mathrm{T}} / \mathrm{V}_{\mathrm{B}}$, or $\mathrm{V}$ function in the literature) is the most important quantity in the theoretical modeling of the track formation mechanism (Fleisher et al., 1975. Mheemeed, et al., 2013). While the measurements of track-opening diameters are relatively straightforward, direct measurements of track lengths are relatively difficult (Hermsdorf, 2009). However, track etch rate, $\mathrm{V}_{\mathrm{T}}$ and sensitivity function $\mathrm{V}$, are usually determined through measurements of track-opening diameters (Hermsdorf and Reichelt, 2010). Analysis of tracks produced by protons, alpha particles or nuclear fission fragments in SSNTDs constitutes a very important tool in various areas (Ilic et al., 2003). For example, the geometrical properties of the cone formation in the SSNTDs can give information about the energy, charge, and the angular distribution of the interacting particles. Direct measurements of track parameters (major and minor axes, depths, etc.) are usually performed by optical methods (Palacios et al., 2011). Independently, two theoretical models for predicting track parameters and profile revealing have been developed by (Fromm et al., 1991, Nikezic and Kostic, 1997). The equivalence of both models has been verified theoretically and experimentally by Dörschel for normal and oblique particle incidence (Dörschel et al., 2003a, and 2003b). Two computer codes (TRACK_TEST and TRACK_VISION) for track parameter and wall profile calculations have been developed and published (Nikezic, and Yu, 2006, Nikezic, and Yu, 2008).

The aim of this work was to present new experimental data on: The bulk etch rate, $\mathrm{V}_{\mathrm{B}}$, angular dependence of major and minor track axes induced by alpha particles in CR-39 in various energies, and track etch rate $V_{T}$, estimate the sensitivity function $V$ for perpendicular case. Calculating track length, $\mathrm{L}$ and track length growth $(\mathrm{dL} / \mathrm{dt})$ for different alpha particle energies and etching times. Study the angular dependence of experimental data of $\mathrm{V}$ function for different alpha particle energies, and finally to compare and discuss experimental $\mathrm{V}$ function for the present work with those for other researchers.

\section{Bulk etch rate measurement}

\section{EXPERIMENTS}

One of the well-known method to determinate the bulk etch rate, $V_{B}$ is the 'gravimetric' method (Kocsis et al., 1997), which is based on the measurements of detector mass before and after etching. A piece of detector material with dimension $(10 \times 10) \mathrm{mm}^{2}$ was weighted first and etched several times in time intervals $2 \mathrm{~h}$, After every etching process the sample was dried and weighted. Based on the mass difference and the known density of the detector, it is possible to calculate $V_{B}$.

\section{Sample irradiation, etching and track axes measurements}

CR-39 detectors samples of dimensions $(5 \times 5) \mathrm{mm}^{2}$ and a thickness $1.5 \mathrm{~mm}$ were irradiated with alpha particles energies from 1 to $5 \mathrm{MeV}$ in steps of $1 \mathrm{MeV}$ through a collimator, and incident angles varied from $20^{\circ}$ to $90^{\circ}$ in steps of $10^{\circ}$ for a reasonable irradiation time of few minutes. The alpha source employed in the present study was a planer ${ }^{241} \mathrm{Am}$ source (activity $1 \mu \mathrm{Ci}$ and main alpha energy $=5.485 \mathrm{MeV}$ under vacuum). In order to obtain different alpha particle incident energies, the relationship between alpha particle energy and distance, given by (Mahesh and 
Mustafa, 1976), was used with normal air (at NTP) as energy absorber. The desired incident angle was restricted by placing the detector on stand with a hole of diameter $1 \mathrm{~mm}$ confront the collimator guiding the alpha particles. Before starting the track analysis, the optical microscope calibration was performed using a micro-grid with known mesh. The detectors were etched by a standard etching condition, $6.25 \mathrm{~N} \mathrm{NaOH}$ solution at $(70 \pm 1) \mathrm{C}^{\circ}$, in a water bath for different time intervals. During etching process, concentration and purity of etching solution were controlled regularly and refreshed every $3 \mathrm{~h}$ usage. After etching, detectors were cleaned in distilled water to remove etchant and etch products from detector surface. Diameters of different alpha-particle energies and incidence angles were measured by means of a semiautomatic system, consisting of an optical microscope (Nikon with magnification of 400x) equipped with (MDCE-5A) digital camera connected to a personal computer for images storage and analyses.

\section{Bulk etch rate measurement}

\section{CALCULATIONS}

The bulk etch rate, $V_{B}$ can be calculated using the relation given by (Kocsis et al., 1997).

$$
\mathrm{V}_{\mathrm{B}}=\frac{1}{2} \frac{1}{\rho \mathrm{A}} \frac{\Delta \mathrm{m}}{\Delta \mathrm{t}}
$$

where $\mathrm{A}$, is the detector surface area in $\left(\mathrm{cm}^{2}\right)$.

$\rho$ is the density of the detector material in $\left(\mathrm{g} \cdot \mathrm{cm}^{-3}\right)$.

$\Delta \mathrm{m} / \Delta \mathrm{t}$, is the slope of the relation between mass difference and etching time.

\section{Track etch rate $V_{T}$}

For perpendicular incident particle a circular track is produced, in which the time dependent major and minor axes are coincide with each other, (i.e. $\left.\mathrm{D}_{\mathrm{maj}}=\mathrm{D}_{\min }=\mathrm{D}\right)$. In this case, track etch rate, $\mathrm{V}_{\mathrm{T}}$ is related to track diameter, $\mathrm{D}(\mathrm{t})$ (Hermsdorf and Reichelt, 2010).

$$
\mathrm{V}_{\mathrm{T}}(\mathrm{t})=\mathrm{V}_{\mathrm{B}} \frac{(2 \mathrm{~h})^{2}+(\mathrm{D}(\mathrm{t}))^{2}}{(2 \mathrm{~h})^{2}-(\mathrm{D}(\mathrm{t}))^{2}}
$$

where $h$, is the removed layer thickness $\left(h=V_{B} \cdot t\right)$.

For oblique incidence the circular track opening changes to elliptical contours with a major axis $D_{\text {maj }}$ and a minor axis $D_{\text {min }}$ where $D_{\text {maj }}$ excites $D_{\text {min }}$ usually. The track etch rate, $V_{T}$ can be calculated according to the formula (Hermsdorf and Reichelt, 2010).

$$
V_{T}(t)=V_{B} \sqrt{\frac{(4 D(t))_{\text {maj }}^{2}(D(t))_{\text {min }}^{2}}{\left(4 h^{2}-(D(t))_{\min }^{2}\right)^{2}}+1}
$$

\section{Track length $L$, track depth $x$, and residual range $R^{\prime}$}

Track length $\mathrm{L}$, track depth $\mathrm{x}$ and residual range $\mathrm{R}$, of alpha particles in detector material can be calculated using the following relations (Dörschel et al., 1996).

$$
\begin{aligned}
& L(t)=V_{T}(t) t-V_{B} t \\
& x(t)=V_{T}(t) t \\
& R^{\prime}=R-V_{T}(t) t
\end{aligned}
$$

where $\mathrm{R}$, is the range of alpha particles in detector material before etching.

Track length growth can be written as (Fromm et al., 2003).

$$
\frac{d L(t)}{d t}=\mathrm{V}_{\mathrm{T}}(\mathrm{t})
$$




\section{V function}

The $\mathrm{V}$ function (sensitivity function, or etch rate ratio) was given as (Hermsdorf and Reichelt 2010).

$$
\mathrm{V}(\mathrm{t})=\mathrm{V}_{\mathrm{T}}(\mathrm{t}) / \mathrm{V}_{\mathrm{B}}
$$

The TRACK-VISION software, provides four V-functions (Mukhtar, 2008), which can be calculated and plot with the present work $\mathrm{V}$ function for comparison.

$$
\begin{aligned}
& \mathrm{V}=1+\left(\mathrm{a}_{1} * \exp \left(-\mathrm{a}_{2} * \mathrm{R}^{\prime}\right)+\mathrm{a}_{3} * \exp \left(-\mathrm{a}_{4} * \mathrm{R}^{\prime}\right)\right) *\left(1-\exp \left(-\mathrm{a}_{5} * \mathrm{R}^{\prime}\right)\right) \text { (Durrani and Bull 1987) ... (9) } \\
& \mathrm{a}_{1}=11.45, \mathrm{a}_{2}=0.339, \mathrm{a}_{3}=4, \mathrm{a}_{4}=0.044, \mathrm{a}_{5}=0.58 \\
& \mathrm{~V}=1+\exp \left(-\mathrm{a}_{1} * \mathrm{R}^{\prime}+\mathrm{a}_{2}\right)-\exp \left(-\mathrm{a}_{3} * \mathrm{R}^{\prime}+\mathrm{a}_{4}\right)+\exp \left(\mathrm{a}_{5}\right)-\exp \left(\mathrm{a}_{2}\right) \quad \text { (Brun function 1999) } \ldots . . .(10) \\
& \mathrm{a}_{1}=0.1, \quad \mathrm{a}_{2}=1, \quad \mathrm{a}_{3}=1, \quad \mathrm{a}_{4}=1.27, \quad \mathrm{a}_{5}=1.27 \\
& \mathrm{~V}=1+\exp \left(-0.068 * \mathrm{R}^{\prime}+1.1784\right)-\exp \left(-0.651 * \mathrm{R}^{\prime}+1.1784\right) \quad \text { (Yu function 2005a) } \\
& \mathrm{V}=1+\exp \left(-0.06082 * \mathrm{R}^{\prime}+1.119\right)-\exp \left(-0.8055^{*} \mathrm{R}^{\prime}+1.119\right) \text { (Yu function 2005b) }
\end{aligned}
$$

\section{Determination of bulk etch rate $\mathrm{V}_{B}$}

\section{RESULTS AND DISCUSSION}

(Fig.1) shows the relationship between mass difference and etching time. The bulk etch rate, $\mathrm{V}_{\mathrm{B}}$ was found experimentally using (Eq.1). From the slope shown in (Fig.1), the known density $\left(1.32 \mathrm{~g} . \mathrm{cm}^{-3}\right)$ and area $\left(1 \mathrm{~cm}^{2}\right)$ of the detector, $V_{\mathrm{B}}$ was found equal to $1.49 \mu \mathrm{mh}^{-1}$.

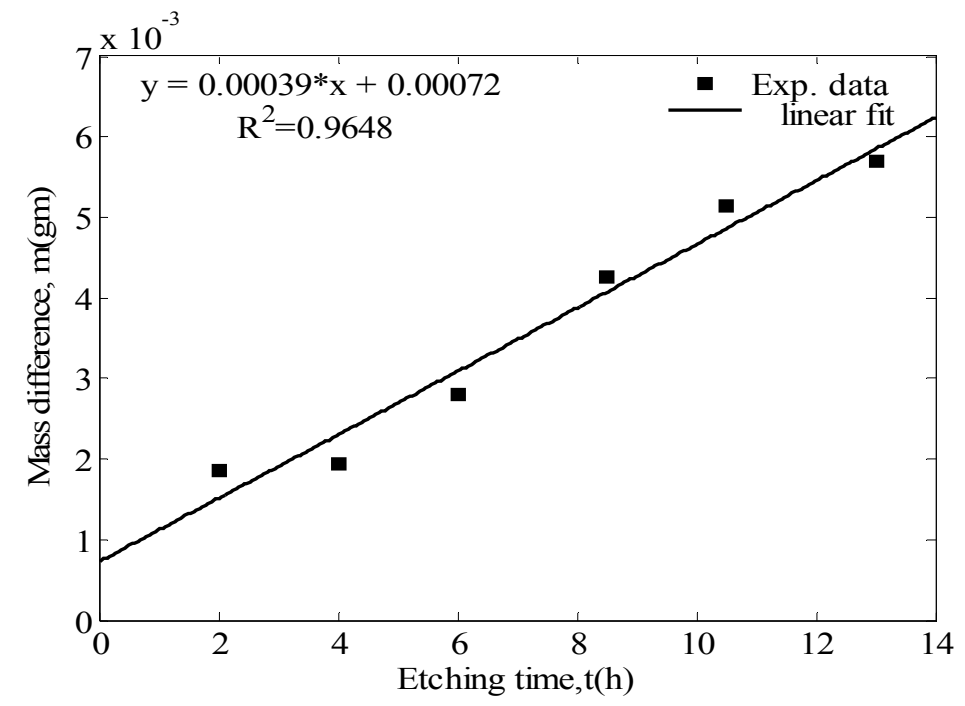

Fig. 1: The relation between the mass difference and etching time.

\section{Track diameter measurements}

The track diameters for normal and oblique incident angles and various energies have been measured using the microscope-camera system. (Fig. 2) presents the relationship of track opening diameter, $\mathrm{D}$ with etching time, $\mathrm{t}$ for normal incidence and alpha particle energy range (1-5) MeV. In general, the important notice indicates exponentially increasing which is in agreement with other studies (Amero et al., 2001). 


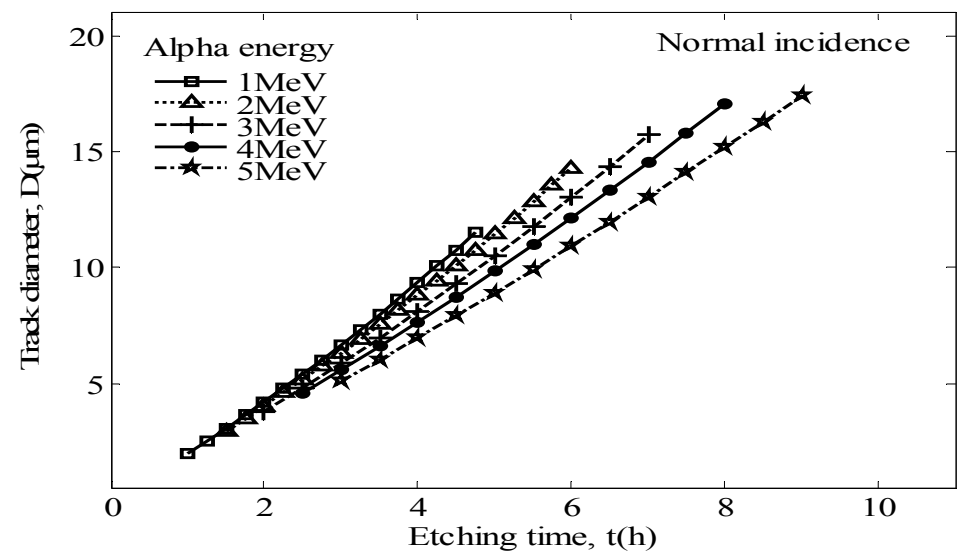

Fig. 2: Track diameter and etching time for different alpha particle energies at normal incidence.

(Fig.3) presents the angular dependence of major axis of the track's opening and alpha particle energy at various incident angles for $8 \mathrm{~h}$ etching time. It is interesting to note that the maximum major axes at $4 \mathrm{MeV}$ alpha particle energy are found for incident angles from $\left(20^{\circ}-40^{\circ}\right)$ but for incident angles from $\left(50^{\circ}-70^{\circ}\right)$ the maximum major axes were found at $3 \mathrm{MeV}$, and for incident angles between $\left(80^{\circ}-90^{\circ}\right)$ the maximum major axes were found at $2 \mathrm{MeV}$.

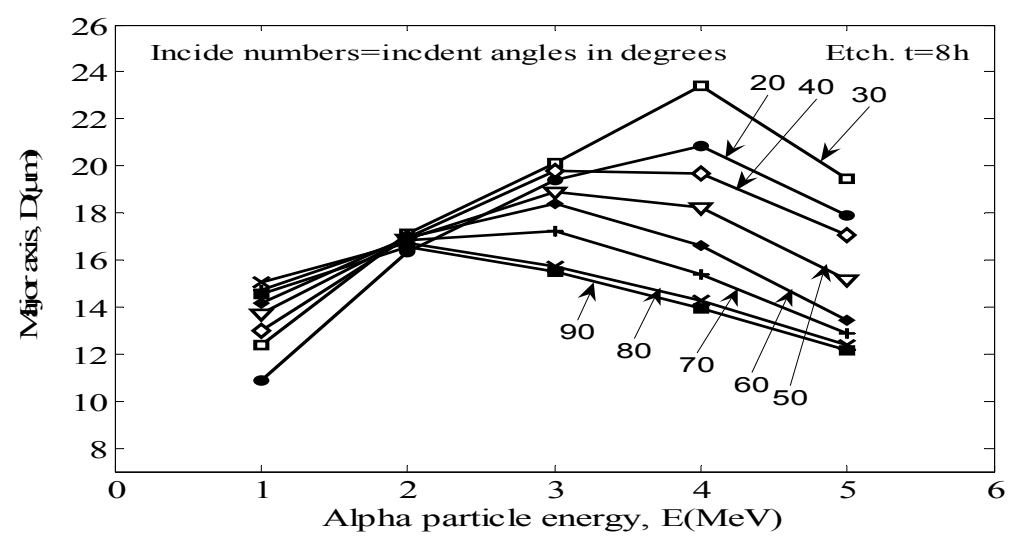

Fig. 3: Major axis with alpha particle energy for various angles.

(Fig. 4) shows the angular dependence of minor axis of the track's opening and alpha particle energy at various incident angles for $8 \mathrm{~h}$ etching time. It is interesting to note that the maximum minor axes for all incident angles occur at $2 \mathrm{MeV}$ alpha particle energy.

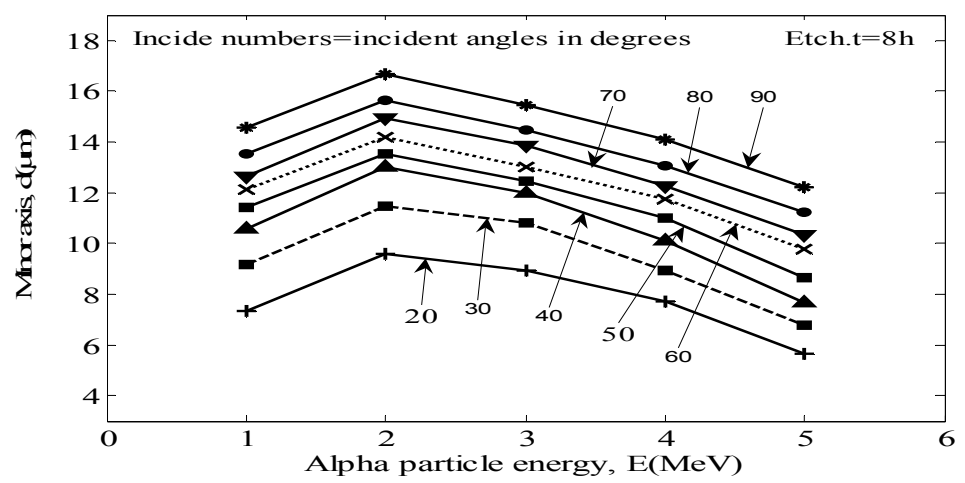

Fig. 4: Minor axis with alpha particle energy for various angles. 
An example of track contours in dependence on the incidence angle is given in (Fig. 5) showing tracks of $5 \mathrm{MeV}$ alpha particles energy etched for $8 \mathrm{~h}$.

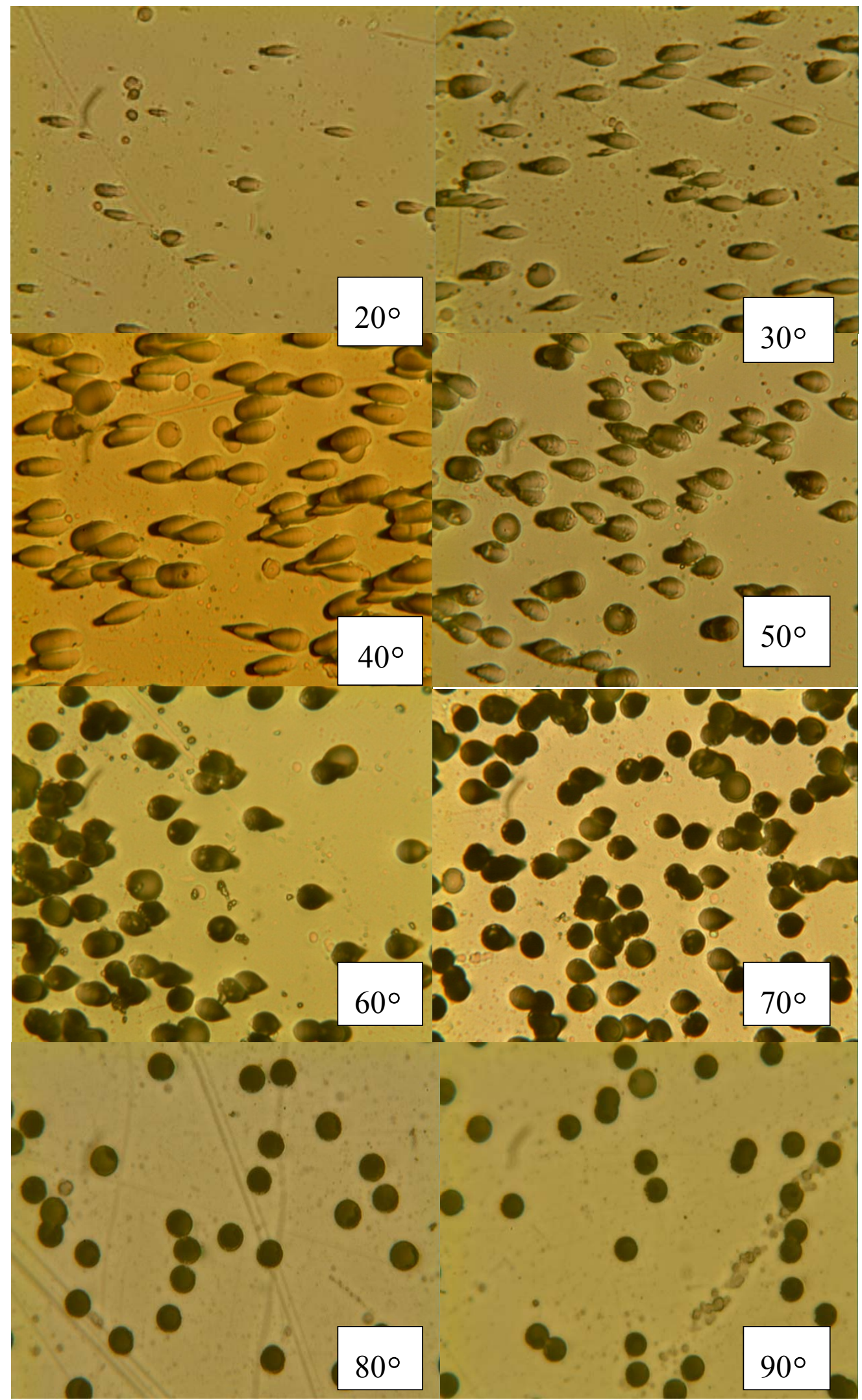

Fig. 5: Track contours after $8 \mathrm{~h}$ etching time at different angles of incidence for $5 \mathrm{MeV}$ alpha particle energy. 
Track etch rate $V_{T}$ versus etching time, $t$ and depth, $x$

(Fig. 6) presents track etch rate, $\mathrm{V}_{\mathrm{T}}$ determined from its relation with track diameter according to (Eq. 2), for normal incidence. The resulting curves differ in the slope for different alpha energies, which reflects the non-linearity of track diameters, $\mathrm{D}$ and they show a distinct spread of the $\mathrm{V}_{\mathrm{T}}$ curves as alpha energy increased. (Fig. 7) presents $V_{T}$ values calculated at a given depth, $x$ from experimental data (Eq. 5). At certain depth, $x$ where $V_{T}$ falls to $V_{B}$, agrees quite well with the range, $\mathrm{R}$ of the alpha particles. The maxima occur approximately at the depths where the Bragg peaks are situated. The positions of the maximum heights increase systematically at higher initial alpha energy. This effect was already found for ${ }^{4} \mathrm{He},{ }^{7} \mathrm{Li},{ }^{11} \mathrm{~B}$ and ${ }^{12} \mathrm{C}$ ions by (Dörschel et al., 2002b).

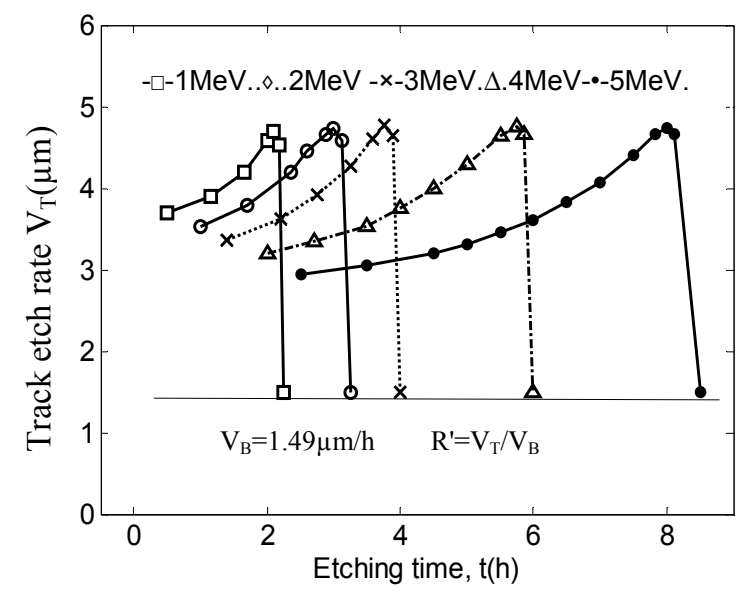

Fig. 6: Track etch rate, $V_{T}$ as a function of etching time, $t$ for various alpha particle energies

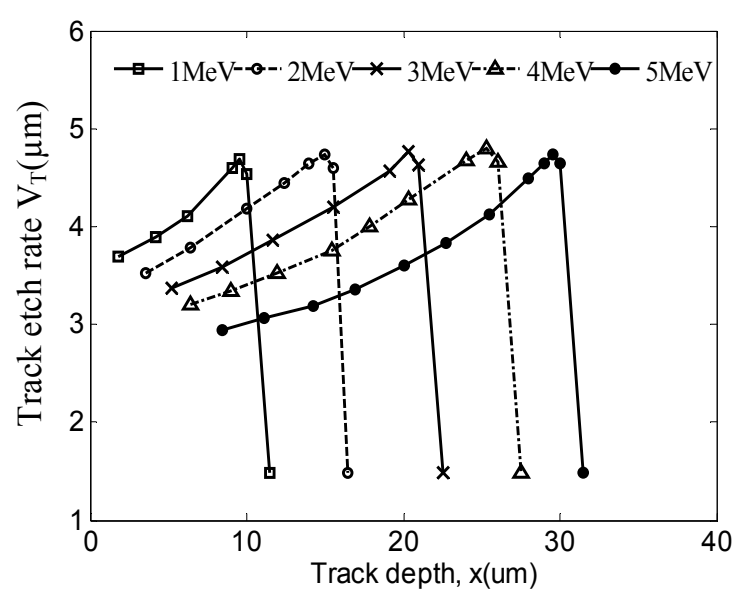

Fig. 7: Track etch rate, $V_{T}$ as a function of track depth, $x$ for various alpha particle energies

\section{Track length, $\mathrm{L}$ and length growth, (dl/dt) versus etching time, $\mathrm{t}$}

(Fig.8) shows the calculated track lengths as a function of the etching time for normal incidence and various energies (Eq. 4). The resulting curves differ in the slope for different alpha energies, which reflects the non-linearity of track etch rate, $\mathrm{V}_{\mathrm{T}}$. After the time needed for etching the total range of incident particle, the track length does not grow further but a saturation behavior occurs. The position of the curves and their maximum heights depend on the particle energy. With increasing energy a shift to longer etching times is visible and the saturation value becomes higher. For etching times larger than the saturation time, the length is determined by $L=L_{\max }+V_{B} t$. This indicates that further etching proceeds with the bulk etch rate. (Fig. 9) shows the track length growth, which represents the curve slope of track lengths (Eq. 7). Track length growth increases with increasing etching time, reflecting the growing track etch rate along the particle trajectory, and then tends to zero value when the end of the particle range was reached. 


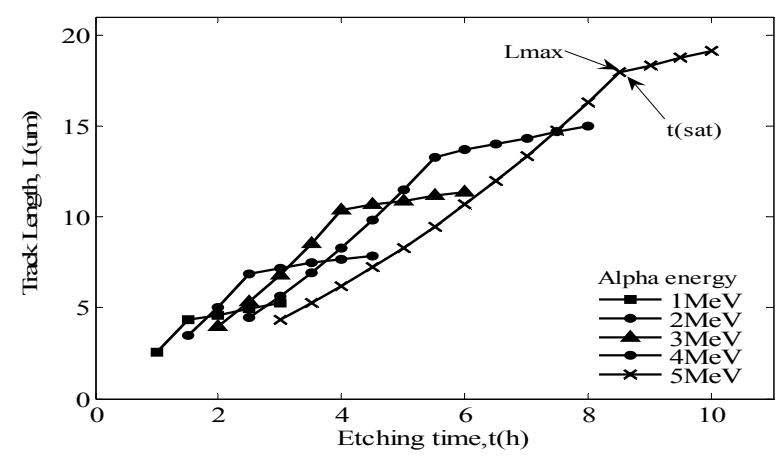

Fig. 8: Track's Length, $L$ as a function of etching time, $t$ for various alpha particle energies.

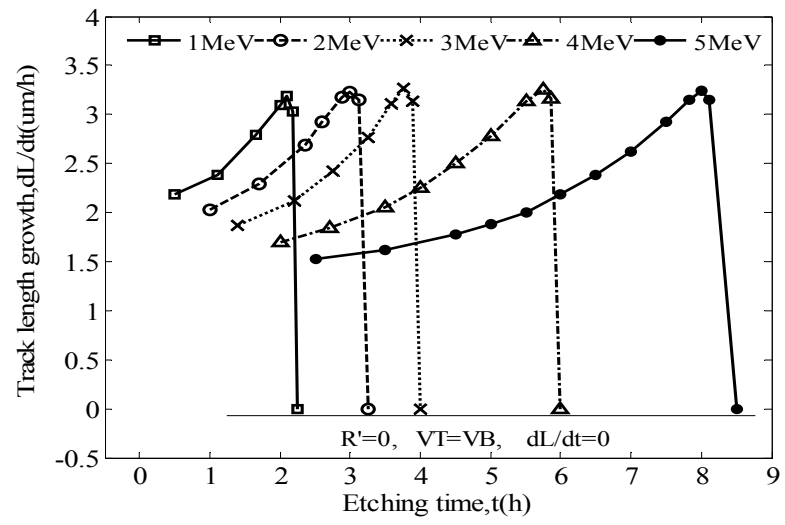

Fig.9: Track's Length growth, dL/dt as a function of etching time, t for various alpha particle energies.

\section{V function (Sensitivity function)}

(Fig.10) presents angular variations of experimental data (Eq.3) of $\mathrm{V}$ function for alpha particle energy range (1-5) $\mathrm{MeV}$, in which it indicates the dependence of sensitivity function $\mathrm{V}$ on the energy loss of the ion along its trajectory (i. e as the energy loss increases the sensitivity function $\mathrm{V}$ increases also).

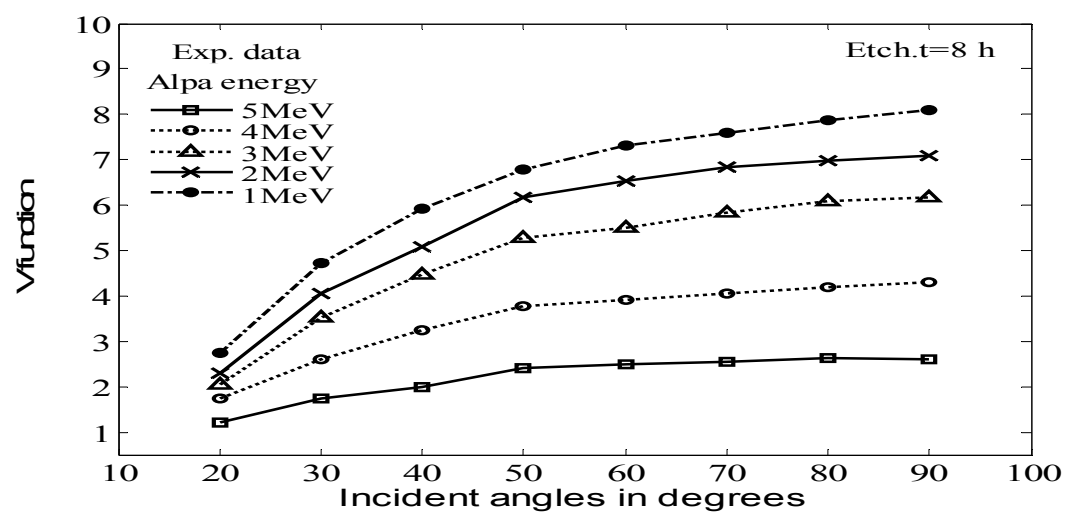

Fig. 10: Experimental $V$ functions versus incident angles for alpha particle energy ranges (1-5) $\mathrm{MeV}$. 
(Fig.11) shows the angular variations of $\mathrm{V}$ function for alpha particle of $5 \mathrm{MeV}$ incidence energy. Experimental data were compared with those computed by the four functions provided in the TRACK_VISION code, which was sited between Durrani-Bull function (1987) and Brun function (1999), and it is nearest to the second one.

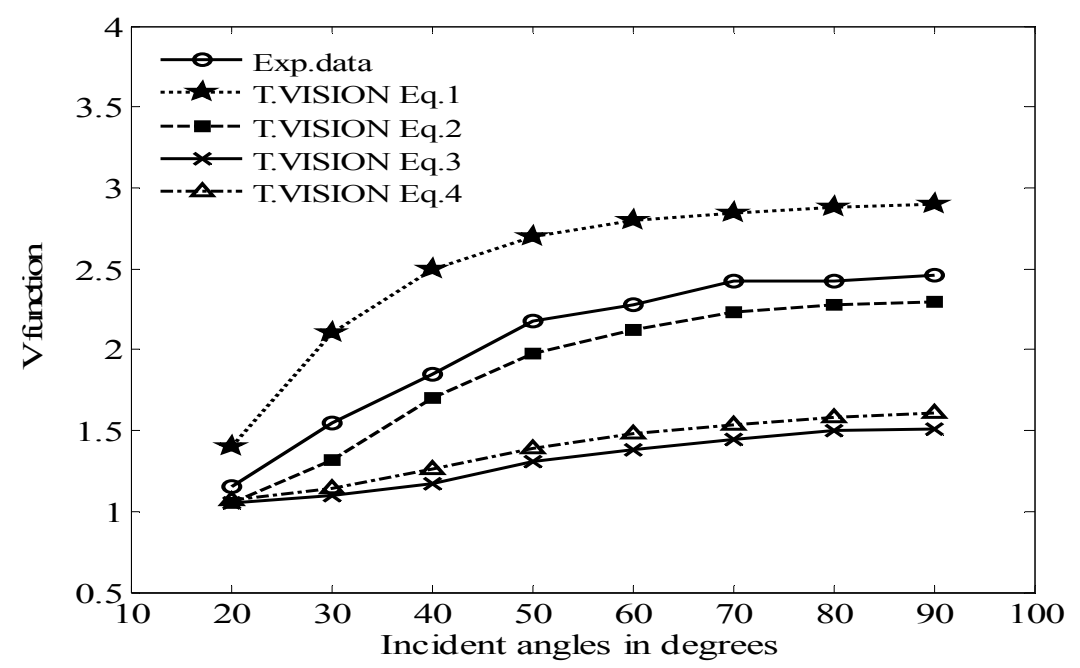

Fig.11: $V$ functions versus incident angles of $5 \mathrm{MeV}$ alpha particle energy, experimental data, with calculated data using TRACK_VISION program.

In the case of perpendicular incidence, the experimental data of sensitivity function $\mathrm{V}$ (Eq.8) was plotted with the residual range, $\mathrm{R}^{\prime}$ (Eq.6) to determine a $\mathrm{V}$ function, which took the functional form of Brun et al., 1999, with a new set of parameters $\left(a_{1}=0.091, a_{2}=1.2, a_{3}=1.6, a_{4}=1.61\right.$, $\mathrm{a}_{5}=1.425$ ) with $\mathrm{R}^{2}=1$. The four expressions for $\mathrm{V}$ function available in the TRACK_VISION software (Eqs.9, 10, 11 and 12), were programmed and plotted in (Fig.12) with our experimental one, for comparison. A maximum appears close to the end of the particle range, which corresponds to the Bragg peak in the stopping power curve. A large difference is observed between Durrani-Bull (1987), and others. The discrepancy is very pronounced in the low energy region around the Bragg peak, at which our function is closer to Brun and $\mathrm{Yu}$ functions, but it is about half the value of Durrani and Bull function. At larger residual ranges, the functions of Durrani-Bull, Brun, and ours are convergent but they are divergent with the two functions of Yu et al., (2005a, and 2005b).

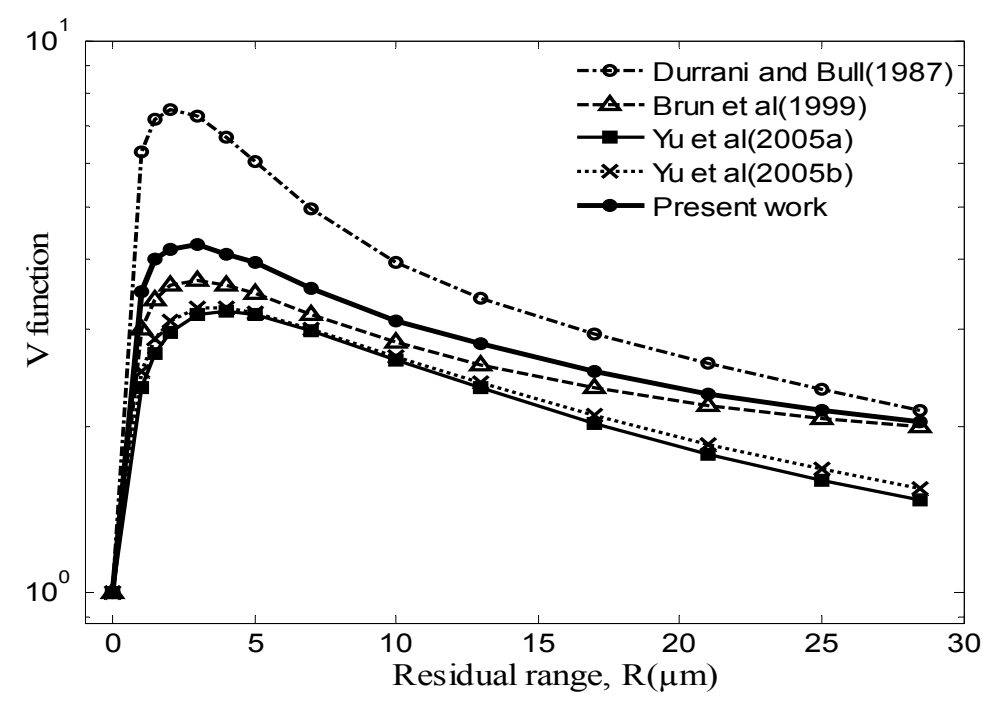

Fig. 12: V function derived from present work with those provided in the TRACK_VISION code for comparison. 


\section{CONCLUSIONS}

The thickness of removed layer is an important factor in all applications of solid state detectors. The mass change method has been applied to measure $V_{B}$, in which a large piece of CR-39 detector was used to avoid uncertainties in the mass difference and surface area measurements. The measured angular dependence of major and minor track axes was used to compute sensitivity function V of CR-39 detector for different alpha particle energies at normal and oblique incident angles. It was found that the track opening diameter and track length non-linear but time dependent. In the present work, we have obtained a $\mathrm{V}$ function with a new set of parameters, which was plotted in (Fig.12) with those computed by TRACK-VISION program for comparison. We can see that the function of Durrani-Bull (1987) has a large difference with the other four functions presented in the figure, while these four functions are relatively commensurate among one another although there are some discrepancies especially at large residual ranges. The accuracy of the calculations depends strongly on the accuracy in the determination of $\mathrm{V}_{\mathrm{T}}$ and $\mathrm{V}_{\mathrm{B}}$ functions.

\section{REFERENCES}

Amero, C.; Golzarri, J.I.; Izerrouken, M.; Espinoas, G. (2001). Gd-148, U-238, Pu-239, Cm-244, Alpha particle energy analysis using tracks in solids. Radiat. Meas. 34, 341-343.

Dörschel, B.; Hartmann, H.; Kadner, K. (1996). Variation of track etch rates along the alpha particle trajectories in two types of CR-39. Radiat. Meas. 26, (51-57).

Dörschel, B.; Hermsdorf, D.; Kadner, K. (2002b). Studies of experimentally determined etch-rate ratios in CR-39 for ions of different kinds and energies. Radiat. Meas. 35, 183-187.

Dörschel, B.; Hermsdorf, D.; Reichelt, U.; Starke, S.; Wang, Y. (2003a). 3D computation comparison with experimental results. Radiat. Meas. 37, 563-571.

Dörschel, B.; Hermsdorf, D.; Reichelt, U.; Starke, S. (2003b). Computation of etched track profiles in CR-39 and comparison with experimental results for light ions of different kinds and energies. Radiat. Meas. 37, 573 - 582.

Durrani, S.A.; Bull, R.K. (1987). "Solid State Nuclear Track Detection: Principles, Methods and Applications". Pergamon Press, Oxford. pp.10-12.

Fleisher, R.L.; Price, P.B.; Walker, R.M. (1975). "Nuclear Track in Solids, Principles and Applications" . University of California Press, Berkley. pp.107-109.

Fromm, M.; Membrey, F.; Chambaudet, A.; Saouli, R. (1991). Proton and alpha track profiles in CR-39 during etching and their implications on track etching models. Nucl. Tracks Radiat. Meas. 19, 163-168.

Fromm, M.; Vaginay, F.; Meesen, G.; Chambaudet, A.; Poffijin, A. (2003). Watching at the correlation between the specific track-etch rate and the primary physical parameters of the swift ion interaction with the CR-39. Radia. Meas. 36, 93-98.

Hermsdorf, D. (2009). Evaluation of the sensitivity function V for registration of $\alpha$-particles in PADC CR-39 solid state nuclear track detector material. Radiat. Meas. 44, 283-288.

Hermsdorf, D.; Reichelt, U. (2010). Measurement of track opening contours of oblique incident 4He and 7Li Ions in CR-39: Relevance for calculation of track formation parameters. Radiat. Meas. 45, 1000-1013.

Hermsdorf, D. (2012). Influence of external and internal conditions of detector sample treatment on the particle registration sensitivity of Solid State Nuclear Track Detectors of type CR-39. Radiat. Meas. 47, 518-529.

Ilic, R.; Skvarc, J.; Golovchenko, A.N. (2003). Nuclear tracks: present and future perspectives. Radiat. Meas. 36, 83-88.

Immè, G.; Morelli, D.; Aranzulla, M.; Catalano, R.; Mangano, G. (2013). Nuclear track detector characterization for alpha-particle spectroscopy. Radiat. Meas. 50, 253-257.

Kocsis, Z.S.; Dwivedi, K.K.; Brandt, R. (1997). Studies on the track formation mechanism of the heavy ions in CR-39. Radiat. Meas. 28, 177-180. 
Mahesh, K.; Mustafa, S.M.(1976)."Nuclear Radiation Detectors and Experiment". Mosul University Press, Iraq. pp.153-154.

Mheemeed, A.K.; Hussein, A.Kh.; Kheder, R.B. (2013). Characterization of alpha-particle tracks in cellulose nitrate LR-115 detectors at various incident energies and angles. Applied Radiation and isotopes 79, 48-55.

Mukhtar Ahmed Rana. (2008). On problems in trustworthy predictions of etched track parameters. Radiat. Meas. 43, 1546-1549.

Nikezic, D.; Kostic, D. (1997). Simulation of the track growth and determination the track parameters. Radiat. Meas. 28, 185-190.

Nikezic, D.; Yu, K.N. (2004). Formation and growth of tracks in nuclear track materials. Material Science and Engineering $R, 46,51-123$.

Nikezic, D.; Yu, K.N. (2006). Computer program TRACK_TEST for calculating parameters and plotting profiles for etch pits in nuclear track materials. Computer Physics Commun. 174, $160-165$.

Nikezic, D.; Yu, K.N. (2008). Computer program TRACK_VISION for simulating optical appearance of etched tracks in CR-39 nuclear track detectors. Computer Physics Commun. 178, 591-595.

Palacios, F.; Palacios Fernández, D.; Ricardo, J.; Palacios, G.F.; Sajo-Bohus, L.; Goncalves, E.; Valin, J.L.; Monroy, F.A. (2011). 3D nuclear track analysis by digital holographic microscopy. Radiat. Meas. 46, 98-103.

Yu, K.N.; Nikezic, D.; Ng, F.M.F.; Leung, J.K.C. (2005). Long-term measurements of radon progeny concentrations with solid-state nuclear track detectors. Radiat. Meas. 40, 560-568. 